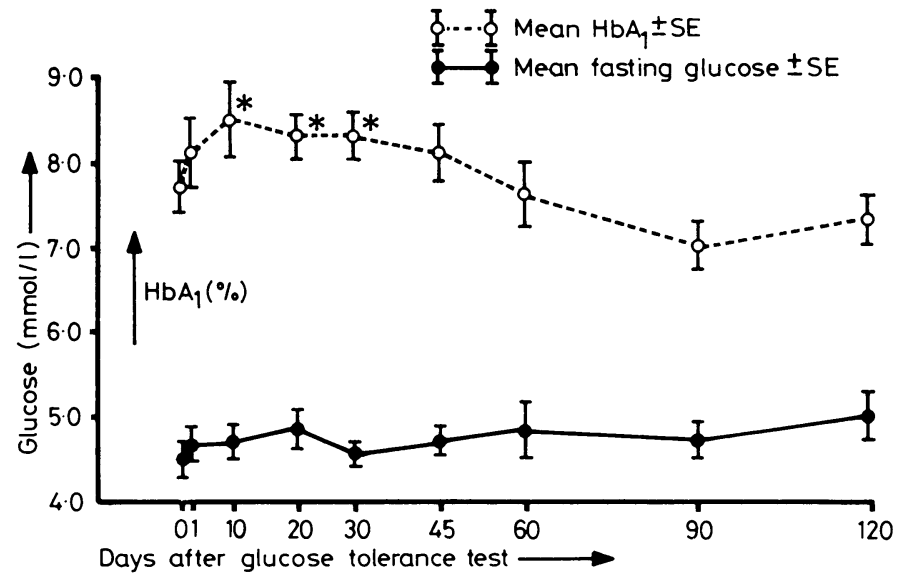

Glucose and $\mathrm{HBA}_{1}$ values in the 120 days after an oral glucose tolerance test. *Result differs significantly from baseline value $(p<0.05)$.

concentration of some $2.5 \mathrm{mmol} / 1$ could produce a significant in rrase in $\mathrm{HbA}_{1}$ concentration of almost $1 \%$ of total haemoglobin and that this increase appeared 10 days after the hyperglycaemia and values remained high until 30 days later, then fell to normal by 60 days after the test. These data differ slightly from those of a similar study ${ }^{2}$ in which $75 \mathrm{~g}$ glucose was used in that we observed a significant rise in $\mathrm{HbA}_{1}$ concentration earlier.

These findings raise doubts about the validity of using $\mathrm{HbA}_{1}$ concentrations as an index of time-integrated blood glucose concentration since the blood sugar concentrations of insulindependent diabetics may vary widely and frequently throughout the day. This criticism would not apply, of course, in uncontrolled or poorly controlled diabetics, in whom persistent significant increases in blood glucose concentrations produce a marked increase in $\mathrm{HbA}_{1}$ values. In these circumstances there is no doubt about the value of $\mathrm{HbA}_{1}$ measurement. Perhaps, however, $\mathrm{HbA}_{1}$ measurements are too sensitive in well-controlled insulin-dependent diabetics and those with mild maturity onset diabetes since our findings show that a minor transient period of hyperglycaemia will result in a significant increase in $\mathrm{HbA}_{1}$ concentrations.

It is now established that there is an unstable component of $\mathrm{HbA}_{1}$ (Schiff base fraction) which accounts for the rapid increase in $\mathrm{HbA}_{1}$ values in response to a short-term increase in blood glucose concentration. ${ }^{3}$ The microcolumn technique does not differentiate between unstable and stable (ketoamine) fractions of $\mathrm{HbA}_{1}$, but an increase in the unstable fraction would be expected to produce some increase in total $\mathrm{HbA}_{1}$. We did not observe this during the glucose tolerance test or the next morning, but possibly the degree of hyperglycaemia might not have been sufficient to produce this effect. Alternatively we may have missed the effect occurring later in the day of the test. The labile fraction is thought to decrease again within six hours, once normoglycaemia is achieved, ${ }^{4}$ so it may have disappeared by the following morning.

We thank Miss Carol Fraser, FIMLS for her invaluable technical help, and Miss Hilary Cox for typing the manuscript.

\section{References}

${ }^{1}$ Bunn HD, Harvey DN, Kasnin S, Gabbay KH, Gallop PM. The biosynthesis of human haemoglobin $A_{1 c}$ : slow glycosylation of haemoglobin in vivo. $\mathcal{f}$ Clin Invest $1976 ; 37: 1652-9$.

${ }^{2}$ Maquart FX, Poynard JP, Borel JP, Leutenegger M. Evolution of haemoglobin $A_{1 c}$ after oral glucose. Lancet 1978;ii:431-2.

3 Anonymous. Haemoglobin $\mathrm{A}_{1}$ and diabetes: a reappraisal. $\mathrm{Br} \mathrm{Med} \mathfrak{F}$ $1980 ; 281: 1304-5$

- Bolli G, Cartechini MG, Compagnucci P, et al. Modification of glycosylated haemoglobin concentration during artificial endocrine pancreas treatment of diabetes. Diabetologia 1980;18:125-30.

(Accepted 14 fuly 1981)

\title{
Carbon monoxide and exercise tolerance in chronic bronchitis and emphysema
}

\author{
P M A CALVERLEY, R J E LEGGETT, D C FLENLEY
}

\begin{abstract}
The effects of carbon monoxide on exercise tolerance as assessed by the distance walked in 12 minutes were studied in 15 patients with severe chronic bronchitis and emphysema (mean forced expiratory volume in one second 0.56 1, mean forced vital capacity 1.54 1). Each subject walked breathing air and oxygen before and after exposure to sufficient carbon monoxide to raise their venous carboxyhaemoglobin concentration by $9 \%$. There was a significant reduction in the walking distance when the patients breathed air after exposure to carbon monoxide $(p<0.01)$, and the significant increase in
\end{abstract}

Royal Infirmary, Edinburgh

P M A CALVERLEY, MB, MRCP, MRC research fellow, department of medicine (now senior registrar)

R J E LEGGETT, MB, MRCP, senior registrar, department of medicine (present appointment: consultant physician, Doncaster Royal Infirmary)

D C FLENLEY, PHD, FRCP, professor of respiratory medicine walking distance seen after exercise when breathing oxygen at $21 /$ minute via nasal cannulae was abolished if carbon monoxide had previously been administered.

Thus concentrations of carboxyhaemoglobin frequently found in bronchitic patients who smoke may reduce their tolerance of everyday exercise, possibly by interfering with the transport of oxygen to exercising muscles.

\section{Introduction}

British cigarettes produce appreciable quantities of carbon monoxide, which is formed by the incomplete combustion of tobacco in those cigarettes without ventilated filters. When inhaled this carbon monoxide readily combines with haemoglobin to form carboxyhaemoglobin. Carboxyhaemoglobin concentration has been related to cigarette consumption, ${ }^{1}$ and concentrations of $5-15 \%$ are common in patients who continue to smoke (table I). In normal healthy volunteers the maximum oxygen uptake during bicycle exercise was reduced when the carboxyhaemoglobin concentration was raised to $20 \%$ by 
inhalation of carbon monoxide, but this effect was seen only at the highest work loads. ${ }^{2}$ Thus carbon monoxide inhaled from cigarettes might contribute directly to the reduced exercise tolerance of patients with chronic bronchitis and emphysema who continue to smoke. We measured the distance walked on the level within 12 minutes in 15 such patients to assess their exercise tolerance before and after they breathed a low concentration of carbon monoxide sufficient to raise their carboxyhaemoglobin concentration by $9 \%$.

\section{Patients and methods}

We studied 15 outpatients (11 men and four women) with severe irreversible airways obstruction (mean $(+S D)$ forced expiratory volume in one second $\left(\mathrm{FEV}_{1}\right) 0.56 \pm 0.2 \mathrm{l}$; mean forced vital capacity (FVC) $1.54 \pm 0.4 \mathrm{l})$ who were hypoxic and retaining carbon dioxide at rest (mean arterial pressure of oxygen $6.83 \pm 0.65 \mathrm{kPa}(51.2 \pm 4.9 \mathrm{~mm} \mathrm{Hg}$ ), mean arterial pressure of carbon dioxide $6.33 \pm 0.7 \mathrm{kPa}(47.5 \pm 5.3 \mathrm{~mm}$ $\mathrm{Hg}$ ); mean arterial $\mathrm{pH} 7 \cdot 39 \pm 0.02$ ) (see table II). All patients were clinically stable at the time of study, and those who smoked were asked to stop smoking for 12 hours before each study. All studies were carried out in the afternoon, the $\mathrm{FEV}_{1}$ and $\mathrm{FVC}$ being measured before and at the end of each study. The results in any patient who showed a change of more than 0.11 in $\mathrm{FEV}_{1}$ during the study period were discarded.

A venous cannula was inserted in the antecubital fossa and blood withdrawn for estimation of carboxyhaemoglobin concentration on attendance, during and after inhalation of $0.02 \%$ carbon monoxide from a Douglas bag, and immediately after the end of the final walk. Carboxyhaemoglobin concentration was measured with an IL 182 Co-oximeter. ${ }^{3}$ In eight patients we also measured arterial oxygen saturation non-invasively using a Hewlett Packard HP47201A ear oximeter before and immediately after the end of the walk. These values were corrected for the carboxyhaemoglobin concentration. ${ }^{4}$

The patients walked at their own pace in a level corridor, the distance walked in 12 minutes (including stops if so desired) being recorded. All patients wore lightweight nasal prongs, giving either air or oxygen at a rate of $2 \mathrm{l} /$ minute delivered from a cylinder that was pushed behind by a technician, who did not know what gas was being given. Six subjects also wore lightweight electrocardiographic chest leads, which permitted recording of the electrocardiogram at the end of the walk. In the other subjects the pulse rate was measured before and at the end of each walk.
Each subject attended on two afternoons and walked four times during each afternoon. After spirometry and blood sampling they walked when breathing $21 \mathrm{air} /$ minute, then sat at rest for 20 minutes, and then walked again breathing 21 oxygen/minute. After another 20minute rest they inhaled $0.02 \%$ carbon monoxide in air from a Douglas bag through a mouthpiece and noseclip for 20-30 minutes until their venous carboxyhaemoglobin concentration was $8-12 \%$ above the initial value measured when they arrived for the study. The two 12-minute walks were then repeated in the same order as before. At the next visit, seven to 14 days later, the order of breathing air and oxygen was reversed, both before and after inhaling carbon monoxide. The results for the two walks were then pooled to eliminate any training effect and to minimise errors due to fatigue. As carbon monoxide is eliminated from the blood with a half life of four hours ${ }^{5}$ it was not possible to repeat the walks with the high carboxyhaemoglobin concentrations first.

The results were analysed by the Wilcoxon signed rank test as normality of distribution could not be assumed. Values were expressed as mean $\pm S D$ or as a range.

\section{Results}

The initial venous carboxyhaemoglobin concentration when the patients were breathing air before exercise was $3 \cdot 1 \%$ (range $1 \cdot 1-5 \cdot 4 \%$ ), and this increased to $12.3 \%$ (range $9 \cdot 6-14.9 \%$ ) after inhalation of carbon monoxide. There was a tendency for the concentration to fall during the second period of exercise, so that the mean at the end of exercise was $10 \cdot 8 \%$ (range $8 \cdot 5-12 \cdot 8 \%$ ). This, however, was a constant effect and affected equally the walks when patients were breathing air and when they were breathing oxygen, as the order of walking was reversed at the end of the second visit. Although the values of FEV and FVC were similar (table II), the distance walked when breathing air varied from 252 to $1075 \mathrm{~m}$ in the different patients and these distances were not significantly correlated with the $\mathrm{FEV}_{1}$ or FVC.

When the distance walked by each patient was compared for the various gas mixtures (figure), breathing 21 oxygen/minute increased the mean distance walked by $53.7 \mathrm{~m}(\mathrm{p}<0.01)$ over that walked when breathing air without a raised carboxyhaemoglobin concentration. Increasing the carboxyhaemoglobin concentration to $12.3 \pm 1.4 \%$ reduced the distance walked when breathing air by $42.7 \mathrm{~m}(\mathrm{p}<0.01)$. When patients had a raised carboxyhaemoglobin concentration and breathed oxygen the mean distance walked increased (as compared with that when breathing air with a raised carboxyhaemoglobin concentration) by $79.3 \mathrm{~m}(\mathrm{p}<0.01)$. The distance walked when

TABLE I-Mean carboxyhaemoglobin concentrations in 91 patients with chronic bronchitis and emphysema attending afternoon outpatient clinic*

\begin{tabular}{lrrrrrrrrrrrrrrrr}
\hline Carboxyhaemoglobin $(\%):$ & $0-1$ & -2 & -3 & -4 & -5 & -6 & -7 & -8 & -9 & -10 & -11 & -12 & -13 & -14 & -15 \\
No of patients: & 5 & 19 & 13 & 8 & 5 & 9 & 6 & 2 & 8 & 2 & 6 & 4 & 3 & & 1 \\
\hline
\end{tabular}

*Patients with concentrations up to $3 \%$ were probably non-smokers.

TABLE II-Spirometric results, arterial blood gas tensions, changes in carboxyhaemoglobin concentrations from baseline values after inhalation of carbon monoxide (CO), and 12-minute walking distance in 15 patients with chronic bronchitis and emphysema

\begin{tabular}{|c|c|c|c|c|c|c|c|c|c|}
\hline \multirow{2}{*}{$\begin{array}{l}\text { Case } \\
\text { No }\end{array}$} & \multirow{2}{*}{$\underset{\text { (I) }}{\mathrm{FEV}_{1}}$} & \multirow{2}{*}{$\underset{\text { (1) }}{\text { FVC }}$} & \multirow{2}{*}{$\underset{(\mathrm{kPa})}{\mathrm{Po}_{2}}$} & \multirow{2}{*}{$\begin{array}{l}\mathrm{PCO}_{2} \\
(\mathrm{kPa})\end{array}$} & \multirow{2}{*}{$\begin{array}{c}\text { Change in } \\
\text { carboxy- } \\
\text { haemoglobin } \\
(\%)\end{array}$} & \multicolumn{4}{|c|}{ Distance walked $(\mathrm{m})$ breathing: } \\
\hline & & & & & & Air & Oxygen & $\begin{array}{l}\text { Air } \\
+ \text { Co }\end{array}$ & $\begin{array}{l}\text { Oxygen } \\
+ \text { CO }\end{array}$ \\
\hline $\begin{array}{l}1^{*} \\
2 \\
3 \\
4 \\
5 \\
6 \\
7^{*} \\
8 \\
9^{*} \\
10 \\
11^{*} \\
12^{*} \\
13 \\
14^{*} \\
15\end{array}$ & $\begin{array}{l}0.5 \\
0.45 \\
0.45 \\
0.65 \\
0.75 \\
0.55 \\
0.55 \\
0.55 \\
1.00 \\
0.60 \\
0.35 \\
0.50 \\
0.60 \\
0.50 \\
0.40\end{array}$ & $\begin{array}{l}1.55 \\
1.60 \\
1.40 \\
1.30 \\
2.05 \\
1.95 \\
1.25 \\
1.20 \\
2.00 \\
1.40 \\
0.90 \\
1.60 \\
2.10 \\
1.80 \\
1.00\end{array}$ & $\begin{array}{l}7 \cdot 2 \\
6 \cdot 8 \\
7 \cdot 5 \\
6 \cdot 1 \\
7 \cdot 7 \\
6 \cdot 3 \\
6 \cdot 7 \\
7 \cdot 1 \\
7 \cdot 1 \\
5 \cdot 2 \\
7 \cdot 1 \\
6 \cdot 5 \\
7 \cdot 3 \\
7 \cdot 5 \\
6 \cdot 4\end{array}$ & $\begin{array}{l}6 \cdot 3 \\
6.5 \\
6 \cdot 3 \\
6.5 \\
5.9 \\
5.7 \\
5 \cdot 6 \\
5.9 \\
5.4 \\
6.9 \\
6.9 \\
7.6 \\
6.1 \\
5.7 \\
7.7\end{array}$ & $\begin{array}{c}11.4 \\
11.0 \\
10.5 \\
10.4 \\
9.1 \\
8.3 \\
8.7 \\
9.8 \\
8.7 \\
8.8 \\
8.0 \\
8.7 \\
8.5 \\
8.0 \\
8.2\end{array}$ & $\begin{array}{r}830 \\
816 \\
835 \\
931 \\
787 \\
724 \\
336 \\
725 \\
872 \\
967 \\
252 \\
1075 \\
347 \\
560 \\
336\end{array}$ & $\begin{array}{r}976 \\
809 \\
874 \\
937 \\
827 \\
738 \\
378 \\
800 \\
898 \\
1006 \\
315 \\
1187 \\
555 \\
672 \\
341\end{array}$ & $\begin{array}{r}730 \\
793 \\
750 \\
918 \\
755 \\
698 \\
210 \\
714 \\
830 \\
903 \\
168 \\
1077 \\
326 \\
558 \\
260\end{array}$ & $\begin{array}{r}870 \\
862 \\
854 \\
918 \\
829 \\
726 \\
279 \\
772 \\
830 \\
955 \\
336 \\
1182 \\
527 \\
642 \\
336\end{array}$ \\
\hline Mean $\pm S \mathrm{D}$ & $0.56 \pm 0 \cdot 16$ & $1 \cdot 54 \pm 0.4$ & $6.83 \pm 0.65$ & $6.33 \pm 0.7$ & $9 \cdot 2 \pm 1 \cdot 1$ & $694 \pm 263$ & $754 \pm 258$ & $646 \pm 280$ & $728 \pm 257$ \\
\hline
\end{tabular}

* Patients known to be current smokers despite medical advice.

$\mathrm{FEV}_{1}=$ Forced expiratory volume in one second. $\mathrm{FVC}=$ Forced vital capacity. $\mathrm{PO}_{2}=$ Pressure of oxygen. PCO $=\mathrm{Pressure}_{2}$ of carbon dioxide.

Conversion: SI to traditional units- $\mathrm{PO}_{2}$ and $\mathrm{PCO}_{2}: 1 \mathrm{kPa} \approx 7.5 \mathrm{~mm} \mathrm{Hg}$. 


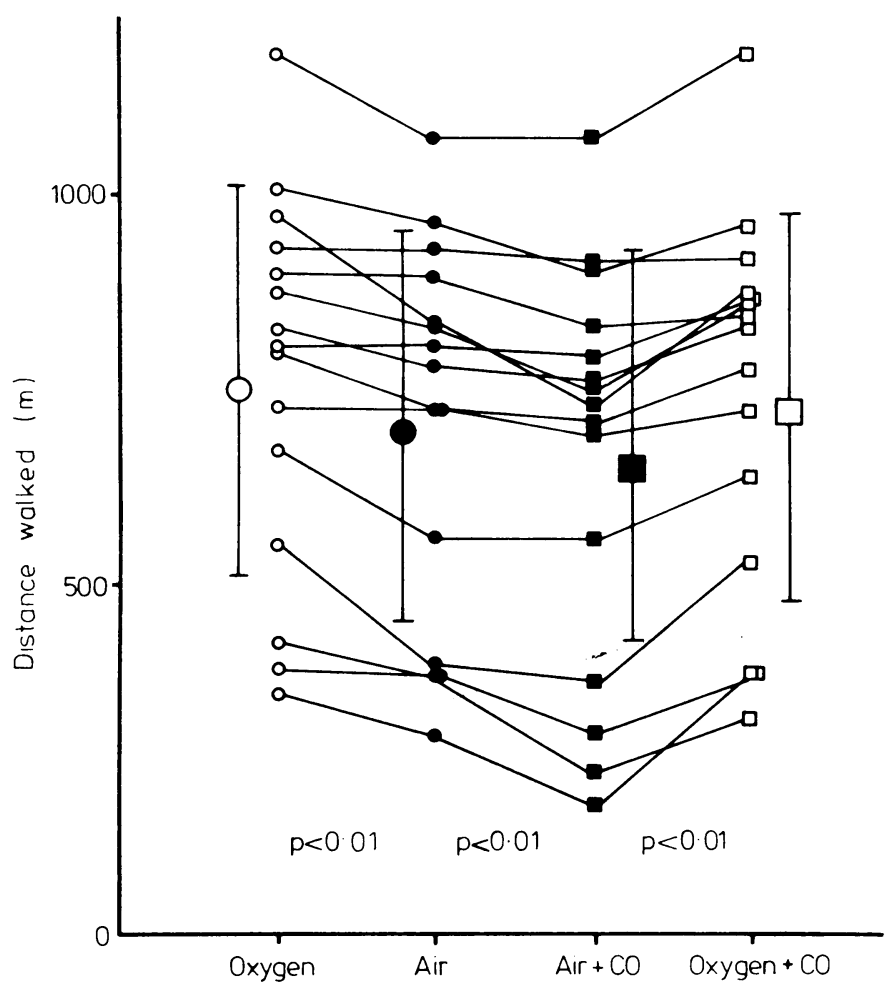

Twelve-minute walking distance, with means $\pm S D$, in 15 patients with chronic bronchitis and emphysema breathing different gas mixtures.

$\mathrm{CO}=$ Carbon monoxide.

breathing oxygen after the carboxyhaemoglobin concentration had been raised was significantly less than that walked when breathing oxygen before the concentration was raised $(p<0.05)$ but was not significantly different from that walked when breathing air before the concentration was raised $(p>0 \cdot 1)$.

The average distance walked did not correlate with the resting arterial oxygen tension when patients were breathing air or with the ear oxygen saturation measured either before or at the end of exercising in the eight patients in whom this was measured. The reduction in distance walked after breathing carbon monoxide was not related to the normal smoking habits of the patients, since it occurred in both current smokers and ex-smokers. The heart rate at the end of the walk was $100-136$ beats/minute, always higher than the $64-88$ beats/minute at rest in each patient. The mean heart rate at the end of exercise, however, was not significantly different when air or oxygen was being breathed, before or after the carboxyhaemoglobin concentration was raised. In three of the six patients in whom an electrocardiogram was recorded at the end of the walk the ST segment was depressed by more than $1 \mathrm{~mm}$, but ST depression was not correlated with breathing any particular gas or with a raised carboxyhaemoglobin concentration.

\section{Discussion}

Cigarette smokers are the non-industrial group most heavily exposed to carbon monoxide, ${ }^{6}$ but the concentrations of carboxyhaemoglobin in smokers are not considered to produce symptoms. Acute carbon monoxide poisoning produces symptoms such as headache, vomiting, and coma only when the carboxyhaemoglobin concentration is over $35 \%$. It has been suggested, however, that chronic exposure to carbon monoxide is associated with subtler changes in neurological function including an impaired ability to distinguish between short intervals of time, which is present even at low carbon monoxide concentrations. ${ }^{7}$ The carboxyhaemoglobin concentrations reached in our studies are less than those that reduce maximal oxygen uptake in normal subjects $^{3}$ but above those that reduce the duration of bicycle ergometer exercise in patients with obstructive airways disease. ${ }^{8}$ The 12-minute walking distance is a simple and reproducible test that correlates well with other subjective and objective variables of exercise tolerance ${ }^{910}$ but is similar to the daily activities that are within the ability of these disabled patients.

We found that raising the carboxyhaemoglobin concentration from values found in non-smokers to values seen in patients who are moderate to heavy smokers reduced the distance that patients with hypoxic chronic bronchitis and emphysema could walk in 12 minutes. We confirmed that breathing 21 oxygen/ minute by nasal prongs can increase the distance walked by such patients ${ }^{11}$ and that this effect of oxygen persists after the carboxyhaemoglobin concentration is raised. The benefit of oxygen on exercise when the carboxyhaemoglobin concentration is raised, however, is less than that before the concentration is raised, and the distance walked when breathing supplementary oxygen at a high carboxyhaemoglobin concentration is not significantly different from that covered when breathing air at the low concentration.

Changes in the oxygen content and oxygen-carrying capacity of the blood are thus associated with measurable changes in everyday exercise in these hypoxic patients. Similar increments in carboxyhaemoglobin concentration in healthy subjects do not affect oxygen delivery to exercising muscles as the cardiac output is increased to compensate. Carbon monoxide, however, reduces the maximal oxygen uptake in healthy people. ${ }^{3}$ There was a considerable variation in the distance walked by different patients, not all of whom showed a dramatic change when the carboxyhaemoglobin concentration was increased (figure). In the eight patients in whom ear oxygen saturation was measured this fell by $3-10 \%$ (mean $6.3 \%$ ) after exercise when breathing air and by $5-18 \%$ (mean $7 \cdot 6 \%$ ) after exercise when breathing air with a raised carboxyhaemoglobin concentration. The fall in arterial oxygen saturation, however, was not related to the distance walked. This variable response may arise from different degrees of physical fitness or from different limitations in the cardiac output response to exercise, so that the delivery of oxygen to the exercising muscle could not be maintained in all patients when the carboxyhaemoglobin concentration was raised.

These studies have shown that continued smoking may play a direct part in the reduction of exercise tolerance seen in patients with severe chronic bronchitis and emphysema. Furthermore, the resultant raised carboxyhaemoglobin concentration would negate any benefit on exercise from treatment with portable oxygen in such patients. Thus even patients with advanced hypoxic chronic bronchitis and emphysema may derive benefit from giving up smoking with a reasonable expectation of an increased exercise tolerance.

\section{References}

${ }^{1}$ Stewart RD, Baretta ED, Platt LR, et al. Carboxyhaemoglobin levels in American blood donors. $f A M A$ 1974;229:1187-95.

2 Vogel JA, Gleser MA. Effect of carbon monoxide on oxygen transport during exercise. 7 Appl Physiol 1972;32:234-9.

${ }^{3}$ Maas HJ, Hamerlink MK, DeLeeuw RJM. Evaluation of the spectrophotometric determination of $\mathrm{HbO}_{2}, \mathrm{HbCO}$ and $\mathrm{Hb}$ in blood with the co-oximeter IL182. Clin Chem Acta 1970;29:303-9.

${ }^{4}$ Douglas NJ, Brash HM, Wraith PK, et al. Accuracy, sensitivity to carboxyhaemoglobin and speed of response of the Hewlett-Packard 47201A ear oximeter. Am Rev Respir Dis 1979;119:311-3.

${ }^{5}$ Forbes WH, Sargent F, Roughton FJW. The rate of carbon monoxide uptake by normal man. Am f Physiol 1945 ;143:594-608.

${ }^{6}$ Stewart RD. The effect of carbon monoxide on humans. Ann Rev Pharmacol 1975;15:409-23.

${ }^{7}$ Beard RR, Wertheim GA. Behavioural impairment associated with small doses of carbon monoxide. Am F Public Health 1967;57:2012-22.

${ }^{8}$ Aronow WS, Ferlinz J, Glauser S. Effect of carbon monoxide on exercise performance in chronic obstructive pulmonary disease. Am $\mathcal{f}$ Med $1977 ; 63: 904-8$.

- McGavin CR, Gupta SP, McHardy GJR. Twelve minute walking test for assessing disability in chronic bronchitis. $\mathrm{Br} M e d \mathcal{F} 1976 ; \mathrm{i}: 822-3$.

${ }^{10}$ McGavin CR, Artvinli M, Naoe H, McHardy GJR. Dyspnoea, disability, and distance walked: comparison of estimates of exercise performance in respiratory disease. $\mathrm{Br}$ Med $\mathcal{F} 1978$;ii :241-3.

$"$ Leggett RJE, Flenley DC. Portable oxygen and exercise tolerance in patients with chronic hypoxic cor pulmonale. $\mathrm{Br} \mathrm{Med} \mathcal{F} 1977$;ii :84-6.

(Accepted 16 fuly 1981) 